\title{
Conductometric Studies of Micellization of Sodium Dodecyl Sulfate in Presence of Non- Polar Additives at Various Temperatures
}

\author{
ANITA D. MUDAWADKAR ${ }^{1}$ and T. J. PATIL ${ }^{2^{*}}$ \\ ${ }^{1}$ Department of Chemistry, K V P'S Kisan Arts, Commerce and Science College, \\ Parola, Dist. Jalgaon 425111 (M.S), India \\ ${ }^{2}$ Department of Chemistry, JET's Z. B. Patil College, Dhule 424002, (M.S.), India \\ tjpatil123@rediffmail.com
}

Received 3 November 2015 / Accepted 20 November 2015

\begin{abstract}
Conductivities of sodium dodecyl sulfate have been determined in water and in the presence of urea and acetamide at 298.15, 303.15, 308.15, 313.15 and 318.15 K. From the specific conductivity data, the critical micellar concentration, degree of counter ion association, degree of counter ion dissociation and standard free energy of micellization, standard enthalpy of micellization and standard entropy of micellization of sodium dodecyl sulfate have been computed. The thermodynamic parameters of micellization and effect of additives on these parameters have been used to study the interactions present in the micellar systems. Surfactants are found to enhance the diffusion significantly depending on hydrophobic/hydrophilic group lengths and the structure of the surfactant molecule. Aggregation properties of sodium dodecyl sulfate (SDS) in the presence of additives like urea and acetamide at various temperatures have been measured by the conductometric study in aqueous solution. The experimental data of aqueous-urea and acetamide solutions as a function of SDS concentration ranging from 1 to $14 \mathrm{mM} \mathrm{dm}^{-3}$ show the presence of inflexion points indicating micellization and interaction mechanisms. CMC of surfactant increases with increase in temperature in a narrows range of composition. Considering $\mathrm{CMC}$ as a function of temperature, various thermodynamic parameters have been evaluated viz: (a) the standard enthalpy change $\left(\Delta \mathrm{H}_{\mathrm{m}}^{0}\right)$, (b) standard entropy change $\left(\Delta \mathrm{S}_{\mathrm{m}}^{0}\right)$ and (c) standard Gibbs energy change $\left(\Delta \mathrm{G}_{\mathrm{m}}^{0}\right)$, The variation in these parameters with the concentration of surfactant and with the change in temperature suggests the manifestation of hydrophobic interactions in the studied system.
\end{abstract}

Keywords: Micellization, Electrical conductivity, Sodium dodecyl sulfate, Urea, Acetamide

\section{Introduction}

The monomers of a surfactant in solution aggregates to from monomer assembly called micelle. The broader threshold limit of monomer concentration called the critical micelle concentration (CMC). Self-association occurs and micelles form. Ideally, the concentration of surfactant monomers remains constant above the CMC and is equal to the CMC value as 
more surfactant is added to the solution. Only the concentration of micelles increases ${ }^{1,2}$. The effect of additives on properties of surfactant solution has been a subject of great significance in a variety of industrial and technological fields ${ }^{3}$.

As a result, detailed investigation of their behavior in aqueous and in presence of additives has recently attracted the attention of several investigators ${ }^{4-6}$. Such a wide application of surfactants is possible because of their unique character of having both hydrophobic groups in the same molecule. The aggregation phenomena of amphiphillic molecules involve contributions from both respective forces interactions. Especially in ionic surfactants, the repulsive forces originated primarily from electrostatic repulsion between the polar head groups ${ }^{7}$. Whereas, attractive interaction have generally been attributed to hydrophobic interactions between the non polar tails of the surfactant monomers $^{8}$. The interactions of these two moieties with water and additives are an important cause for surfactants to aggregate in to micelles and other nano-meter scale structures in aqueous solution ${ }^{6}$. The study of specific and non specific interaction of surfactants with additives has been a subject of extensive research due to its diverse importance ${ }^{9}$. However, in order to have fine details, the interactions of basic structural units of proteins (i.e.amino acids) with surfactants must be studied owing to the complex structure of the biological macromolecules ${ }^{10}$. The side chains of these building blocks differ in size, shape, charge, hydrogen-bonding capacity, hydrophobicity and chemical reactivity. Individually and collectively, these side chains contribute to the structure and function of protein ${ }^{7}$. Acetamide is considered to be strong structure-breakers in aqueous solutions due to the presence of peripheral charges ${ }^{8}$. Urea is an important fertilizer due to its wide range of applications in crop production. On the other hand, the commonly used surfactant sodium dodecyl sulfate (SDS) is reported to act as a more potent protein denaturant than urea and guanidine hydrochloride ${ }^{11}$. In continuation of our studies on thermodynamic parameters, we report here the effect of urea and acetamide on the micellization of sodium dodecyl sulfate in aqueous medium.

Hydrophobic interactions cause the apolar groups to associate in a hydrocarbon- like core, with polar or ionic head groups at the surface in contact with water ${ }^{12}$. Electrolytes generally facilitate the formation of ionic micelles, primarily by lowering the coulombic free energy at the interface resulting in a decrease in critical micelle concentration and an increase in the micellar aggregation number. So that, at high ionic strength huge surfactant aggregates is formed ${ }^{13}$. On the other hand, non-electrolyte organic additives, which can be further classified as polar and non-polar, affect micellization in different way depending on the nature of the additives as well as its quality ${ }^{13}$. Therefore, the properties of surfactant solutions, are differently affected in presence of additives. The present work becomes interesting because the behavior of urea/acetamide in aqueous solutions is somewhere between strong electrolytes and non-electrolytes ${ }^{14}$. Surfactants are amphiphillic molecules that possess both hydrophobic and hydrophilic properties. A typical surfactant molecule consists of a long hydrocarbon 'tail' that dissolves in hydrocarbon and other non-polar solvents and a hydrophilic 'head group' that dissolves in polar solvents (typically water). One example of a dual character molecule having a head-group and a non-polar tail is sodium dodecyl sulphate (SDS), $\mathrm{Na}^{+}{ }^{-} \mathrm{OSO}_{3} \mathrm{C}_{12} \mathrm{H}_{25}$. When a sufficient amount of SDS is dissolved in water, several bulk solution properties are significantly changed, particularly the surface tension (which decreases) and the ability of the solution to solubilize hydrocarbons, (which increases). These changes do not occur until a minimum bulk SDS concentration is reached. 
Several experiments, including light scattering and NMR, show that below the CMC, the surfactant exists mainly as solvated monomeric species, whereas above the CMC these monomers undergo self-assembly to form roughly spherical structures (having an overall diameter of $\sim 5 \mathrm{~nm}$ ) known as micelles. Micelles are the simplest cluster of all self-assembly of monomers.

Technically, a micellar solution is a colloidal dispersion of organized surfactant molecules. Non-ionic surfactant molecules can cluster together in micelles of 1000 molecules or more, but ionic species tend to form micelles of between 10 and about 100 molecules because of electrostatic repulsions between head-groups. One of the key aspects of micelle structure is that the interior of the micelle consists of an associated arrangement of hydrocarbon chains (an 'oil droplet'). The exterior coat is constructed of the polar, ionic moieties (the $\mathrm{OSO}_{3}$-groups in the case of SDS). This ionic surface (which also contains associated water of hydration) is called the Stern layer. Surrounding this ionic mantle is a region that contains both counter ions and oriented water molecules - the Gouy-Chapman layer. Together the Stern and Gouy-Chapman layers are known as the electrical double layer. But it is the oil-like interior of the micelle that gives it its many diverse and interesting properties. The hydrocarbon core $(\sim 3 \mathrm{~nm}$ in diameter) has the capacity to accommodate guest molecules. The most common application of micelles is as detergents but they can also act as micro-reaction vessels for organic syntheses and drug delivery agents

In this experiment we were determined some fundamental properties of the SDS micelle: the CMC and the free energy, enthalpy and entropy of micellisation. We were measure the CMC by measuring the conductivity of the system as a function of SDS concentration. The thermodynamic properties are obtained by determining the CMC at a variety of temperatures. Although numerous studies on the effects of additives of varied natures on micellization have been reported in the literature ${ }^{13-15-18}$ relatively very few studies are available on the effect of urea and acetamide on the micellization of SDS at different temperatures. The conductometric technique has been found to be highly useful for studying the solution behavior of various systems, including surfactants ${ }^{6,16,17,19,20}$. To the best of our knowledge no work has been reported in the study of SDS in aqueous urea and acetamide at different temperatures.

These considerations leds us to investigative the effects of the zwitterionic molecules, i.e. urea and acetamide on the micellization of anionic surfactant SDS in aqueous solutions at a wider range of temperature and surfactant concentration using conductivity method. Moreover, various important thermodynamic parameters such as the standard free energy of micellization, $\Delta \mathrm{G}_{\mathrm{m}}^{0}$ the standard enthalpy of micellization, $\Delta \mathrm{H}_{\mathrm{m}}^{\mathrm{o}}$, the standard entropy of micellization $\Delta S^{0}$, the group of urea and acetamide on these parameters.

\section{Experimental}

The additives urea and acetamide was the product of sigma Aldrich, USA (Urea mol. wt. 60.60 and Acetamide mol. wt. $59.07 \mathrm{~g} / \mathrm{mol}$ ). Both the additives are dialyzed to remove low molecular weight fractions and other associated electrolytic impurities before use. Deionized doubly distilled water having a specific conductivity in the range $1-2 \times 10^{-6} \mathrm{Scm}^{-1}$, at $303.15 \mathrm{~K}$ was used in the preparations of all solutions of different concentrations.

Sodium dodecyl sulfate (SDS) Mol.wt $288.38 \mathrm{~g} / \mathrm{mol}$ (Central Drug House Ltd., Mumbai, massfraction $>0.99$ ) was used after recrystallization from ethanol and was dried in a vacuum over $\mathrm{P}_{2} \mathrm{O}_{5}$. Water with conductivity, $1.05 \times 10^{-6} \mathrm{Scm}^{-1}$ at $298.15 \mathrm{~K}$ was used for preparation of solution and was obtained by distilling deionized water from alkaline $\mathrm{KMnO}_{4}$ 
to remove organic matter, if any stock solutions of $0.10 \mathrm{M}\left(\mathrm{mol} \mathrm{kg}^{-1}\right)$ SDS in order to cover the pre- and post-micellar concentration range of SDS. The weighing's were done on a precise XB-220 A, Swiss make electronic balance with a precision of $\pm 0.001 \mathrm{~g}$. All necessary precautions were taken to prepare solutions. The solutions were stored in special airtight bottle to minimize absorption of atmospheric moisture and carbon dioxide.

Conductivities of the solutions were measured with Conductivity meter, Systronic Model 306, India, having a cell constant $1.007 \mathrm{~cm}^{-1}$. The conductivities of the solutions of potassium chloride (Merck, purity $>99 \%$ ) of different concentrations $0.01 \mathrm{~N}$ and $0.1 \mathrm{~N}$ were used to determine the cell constant. The solution and the measuring cell were immersed in an electronically controlled thermostated water bath, maintaining the temperature within $\pm 0.02 \mathrm{~K}$. Specific conductivities were measured in a Knick microprocessor conductivity meter provided with a four-pole measuring cell (the measured cell-factor was equal to $1.10 \mathrm{~cm}^{-1}$ ) and temperature sensor, using solutions prepared with doubly distilled water. The solutions were thermostated in the conductivity cell, equipped with a magnetic stirring device.

\section{Results and Discussion}

\section{Effect of temperature on CMC of SDS}

The experimental values of the conductivity (k) of SDS in $0.2 \mathrm{M}, 0.4 \mathrm{M}, 0.6 \mathrm{M}$ and $0.8 \mathrm{M}$, aqueous urea and acetamide as a function of surfactant concentration at 298.15, 303.15 308.15, 313.15 and $318.15 \mathrm{~K}$ are reported. The values of CMC's of pure substance with additives have been obtained from the intersection of the fitting lines of the conductivity versus concentration plots above and below the break point, as a function of temperature are reported. The dependence of $\mathrm{k}$ on [SDS] and temperature in presence and absence of additives is graphically studied. The variation of specific conductance and concentration of SDS in aqueous medium, in urea and acetamide at are shown in Figure 1,2 and 3. The observed CMC values of SDS in aqueous solutions are $8.26,8.3,9.09$, and $9.9 \times 10^{-3} \mathrm{~mol} / \mathrm{kg}$ at $298.15,303.15,308.15$ and $313.15 \mathrm{~K}$ respectively, which compare well with the literature ${ }^{21,22}$ values $8.0 \times 10^{-3} \mathrm{~mol} / \mathrm{dm}^{-3}$ at 298.15 $\mathrm{K}$ and $308.15 \mathrm{~K} ; 8.2$ and $8.7 \times 10^{-3} \mathrm{~mol} \mathrm{~L}^{-1}$ at 303.15 and $313.15 \mathrm{~K} ; 8.15,8.40$ and 8,40 mol L $\mathrm{L}^{-1}$ at $298.15,303.15$ and $308.15 \mathrm{~K}$ respectively ${ }^{23}$.

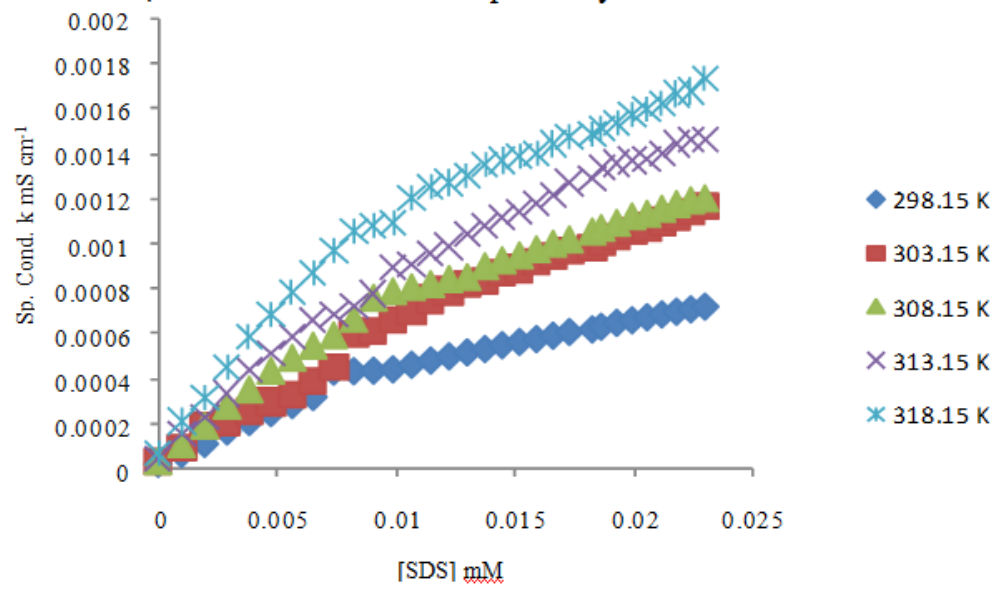

Figure 1. Variation of specific conductance with concentration of SDS in aqueous medium at different temperatures 


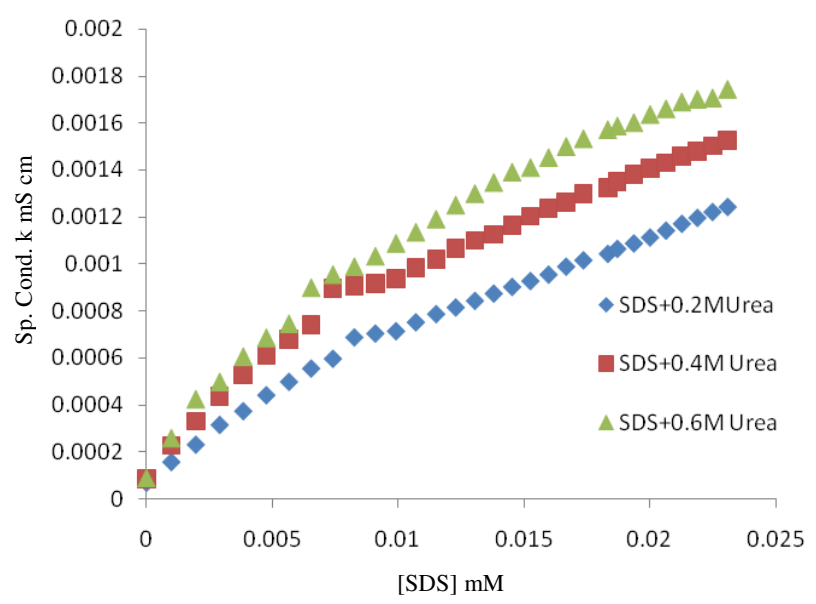

Figure 2. Effect of concentration of urea on specific conductance of SDS in aqueous medium at $\mathrm{T}=308.15 \mathrm{~K}$

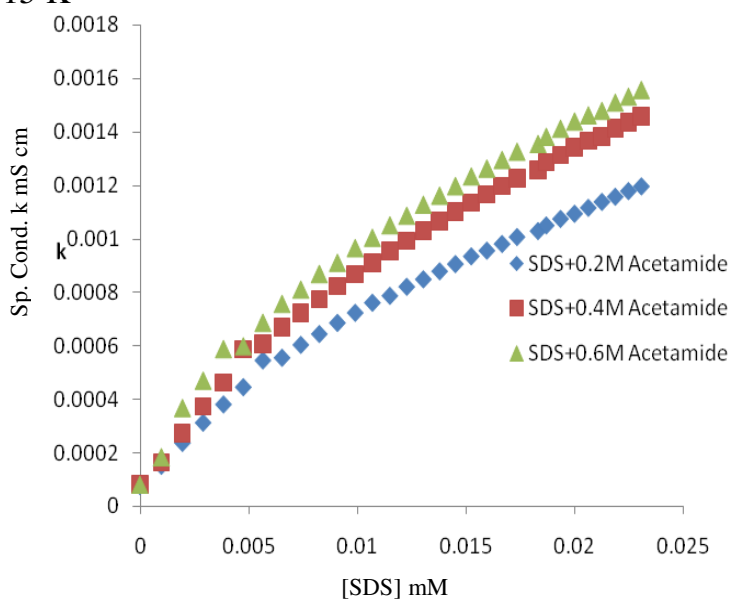

Figure 3. Effect of concentration of acetamide on specific conductance of SDS in aqueous medium at $\mathrm{T}=308.15 \mathrm{~K}$

\section{CMC of SDS-Urea system}

The CMC of SDS both in aqueous and in urea increases with increase in temperature (Table 1). The effect of temperature on the CMC of surfactant in aqueous medium is complex ${ }^{24}$. In general, the effect of temperature on the CMC of surfactants in aqueous medium is analyzed in terms of two opposing effects ${ }^{17,20,24}$, (i) CMC first tend to decrease causes decrease in hydration of hydrophilic group, which favor micellization. (ii) However, at relatively higher temperature range disruption of the structural water surrounding the hydrophobic group occurs, this disfavors, micellization ${ }^{25,26}$, thereby increasing the CMC of the surfactant.

\section{CMC of SDS-Acetamide system}

It is clear from the Table 1 that the second effect seems to be dominant over the first one for the present system, in the temperature range studied. Our finding is supported by the fact that for ionic surfactants, minimum in the CMC temperature range curve appears around $298 \mathrm{~K}$ and thereby ${ }^{24}$ increasing the $\mathrm{CMC}$ of the surfactant. It is clear that CMC tends to increase, 
as for SDS in this case, with increase in the temperature. Furthermore, Table 1 and 2, exhibits the sequence: on water $>$ urea $>$ Acetamide at each investigated temperature. It is well known that the micellization process occurs due to the hydrophobic interactions and that dispersion force is the attractive force in the micellization ${ }^{26,27}$.

Table 1. CMC's and degree of ionization ( $\beta$ ) of SDS with Urea at different concentration and temperatures

\begin{tabular}{ccccc}
\hline \multirow{2}{*}{$\begin{array}{c}\text { Temperature, } \\
\text { K }\end{array}$} & \multirow{2}{*}{ SDS } & \multicolumn{3}{c}{ SDS + [Urea] } \\
\cline { 2 - 5 } & & \multicolumn{3}{c}{ CMC, mM } \\
\hline 298.15 & 0.0074 & 0.0065 & 0.0056 & $0.6 \mathrm{M}$ \\
303.15 & 0.0083 & 0.0074 & 0.0065 & 0.0047 \\
308.15 & 0.0091 & 0.0082 & 0.0074 & 0.0065 \\
313.15 & 0.0990 & 0.0090 & 0.0082 & 0.0074 \\
318.15 & 0.0107 & 0.0099 & 0.0090 & 0.0082 \\
& & \multicolumn{3}{c}{$\beta$} \\
298.15 & 0.29 & 0.33 & 0.39 & 0.42 \\
303.15 & 0.38 & 0.37 & 0.43 & 0.45 \\
308.15 & 0.46 & 0.41 & 0.47 & 0.48 \\
313.15 & 0.53 & 0.45 & 0.51 & 0.51 \\
318.15 & 0.59 & 0.49 & 0.55 & 0.54 \\
\hline
\end{tabular}

Table 2. CMC and degree of ionization ( $\beta$ ) of SDS with Acetamide at different concentration and temperatures

\begin{tabular}{cccc}
\hline Temperature, & \multicolumn{3}{c}{ SDS + [Acetamide] } \\
\cline { 2 - 4 } $\mathrm{K}$ & $0.2 \mathrm{M}$ & $0.4 \mathrm{M}$ & $0.6 \mathrm{M}$ \\
\cline { 2 - 4 } & \multicolumn{3}{c}{$\mathrm{CMC} \mathrm{mM}$} \\
\hline 298.15 & 0.0038 & 0.0029 & 0.0019 \\
303.15 & 0.0047 & 0.0038 & 0.0029 \\
308.15 & 0.0056 & 0.0047 & 0.0038 \\
313.15 & 0.0065 & 0.0056 & 0.0047 \\
318.15 & 0.0074 & 0.0065 & 0.0056 \\
& & & $\beta$ \\
298.15 & 0.60 & 0.63 & 0.67 \\
303.15 & 0.63 & 0.66 & 0.71 \\
308.15 & 0.66 & 0.69 & 0.74 \\
313.15 & 0.69 & 0.72 & 0.77 \\
318.15 & 0.73 & 0.75 & 0.81 \\
\hline
\end{tabular}

Thus, as the number of carbon atoms increases from urea to acetamide so does the hydrophobic character of the molecules. The increase in hydrophobic interaction requires a lower addition of surfactant molecules for micellization ${ }^{27}$, resulting in a decreased CMC in the presence of urea and acetamide. Sodium dodecyl sulfate (SDS), $\mathrm{NaOSO}_{3} \mathrm{C}_{12} \mathrm{H}_{25}$ is known as amphiphilic surfactant which possesses both hydrophobic and hydrophilic properties. SDS was ionized in the aqueous solution to form $\mathrm{Na}^{+}$and ${ }^{-} \mathrm{OSO}_{3} \mathrm{C}_{12} \mathrm{H}_{25}$ ions in the solution. Self-dissociation of SDS into micelle is strongly cooperative and occurs at the defined concentration called critical micelle concentration. Below CMC, the amphiphile dissolves as monomers. Once the concentration beyond $\mathrm{CMC}$, the monomers concentration remains unchanged while the micelle concentration increases. The CMC can be determined by the conductivity method of the SDS solution. $\mathrm{Na}^{+}$and ${ }^{-} \mathrm{OSO}_{3} \mathrm{C}_{12} \mathrm{H}_{25}$ ions are known as charge carriers which will increase the conductivity of the solution when ionization takes place ${ }^{28}$. 
In a SDS dilute solution, the concentration of SDS is below its CMC, hence it behaves as normal electrolyte and ionizes to give out $\mathrm{Na}^{+}$which soluble in the aqueous phase while ${ }^{-}$ $\mathrm{OSO}_{3} \mathrm{C}_{12} \mathrm{H}_{25}$ ions solubilize its hydrophilic head in the water and hydrophobic tail extent out the water surface. The ions exist as solvated monomer instead of micelle due to low SDS concentration. The number of monomers was increased as the amount of the SDS solution was added into the solution. At the same time, the increase of conductivity that had been detected due to the increase of SDS ions carried more charges within the solution. Once the amount of SDS solution added into the aqueous solution is equals to the CMC, the first micelle start to form spontaneously in the solution ${ }^{28}$.

The micelle formation occurs just above of CMC at which the monomers undergo selfassembly to form aggregate in the solution and the homogeneous solution becomes a colloidal system. The micellar solution is known as a colloidal dispersion (association colloid) of organized surfactant molecules. The micelle formed in the solution would have spherical structure in which the hydrophilic head groups were exposed to the solution while the hydrophobic tails were faced toward the interior of the micelle structure. The exterior of the micelle is built up from the ionic ${ }^{-} \mathrm{OSO}_{3}$ groups which form the Stern layer which associated by water molecules. The further layer that surrounding the Stern layer is composed of the positive counter ions and oriented water molecule called Gouy-Chapman layer. Both Stern layer and Gouy-Chapman layer are known as electric double layer. This double layer will maintain the stability of the colloidal system ${ }^{28}$.

The higher concentration of SDS caused nucleation for the micelle to form increased and hence more micelle was formed in the solution. Above the CMC, the concentration of micelle definitely increases. However, the concentration of monomers almost remained unchanged in the solution. Monomers tend to form the micelle at the same time the added SDS solution ionized in the solution to replace the monomers that used to build micelle. But, the charge carriers could be increased slowly because the rate of micellization is slower than the rate of monomers were used in the building of micelle and hence the conductivity of the solution increased at a slower rate in an ideal condition. This can be noticed in the Figure 1, 2 and 3 which shows the increasing rate of conductivity had became slower obviously. This is because the formation of micelle required the ionic monomers and some of the ions had been attracted towards the micelle surrounding to form the electric double layer. As a result, some monomers are no longer free in the solution but for those ions are not strongly attracted still can carry charge in the solution. Hence, the conductivity of the solution increased slower. However, at the final part in graph (Figure 1, 2 and 3) shows a sudden increase in the conductivity of the may be due to the formation of bubbles inside the solution. Above the CMC, when bubbles start forming, micelles will be broken down to form monomers to expand the bubbles. As more SDS monomers being formed back, the conductivity shoot up because SDS monomers is a more effective charge carrier than micelles ${ }^{28}$.

The effect of temperature on critical micelle concentration of SDS and additives are studied. The $\ln \mathrm{X}_{\mathrm{CMC}}$ increases with increase in temperature for SDS (Figure 4), SDS + Urea (Figure 5) and SDS + Acetamide (Figure 6).

This may also be explained by considering the zwitterionic nature of urea/acetamide additives, which interest with the water molecules, causing dehydration of the hydrophilic head of the surfactant micelles ${ }^{26}$. This, in turn favors micellization, thereby, leading to a decrease in CMC of SDS in the presence of urea and acetamide. A similar decrease in CMC of SDS upon addition of amino acids in aqueous medium has also been reported by others ${ }^{22}$. 


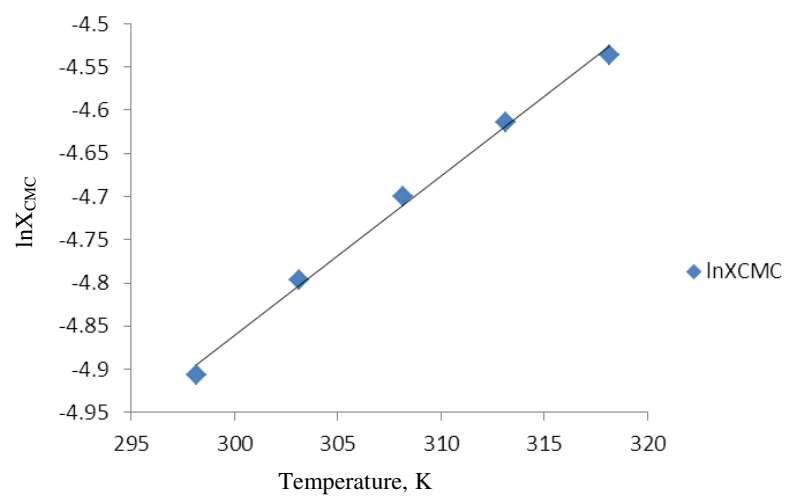

Figure 4. Variation of $\ln \mathrm{X}_{\mathrm{CMC}}$ of SDS with temperature

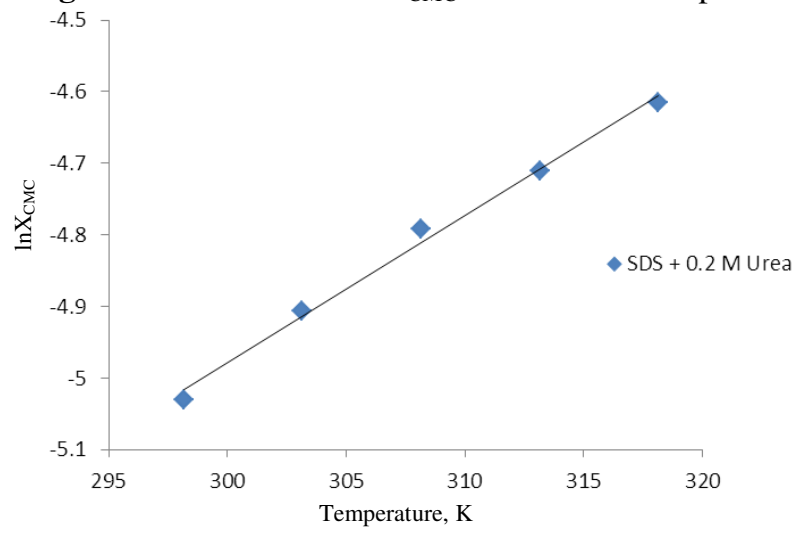

Figure 5. Effect of $0.2 \mathrm{M}$ Urea on $\ln \mathrm{X}_{\mathrm{cmc}}$ of SDS at different temperatures

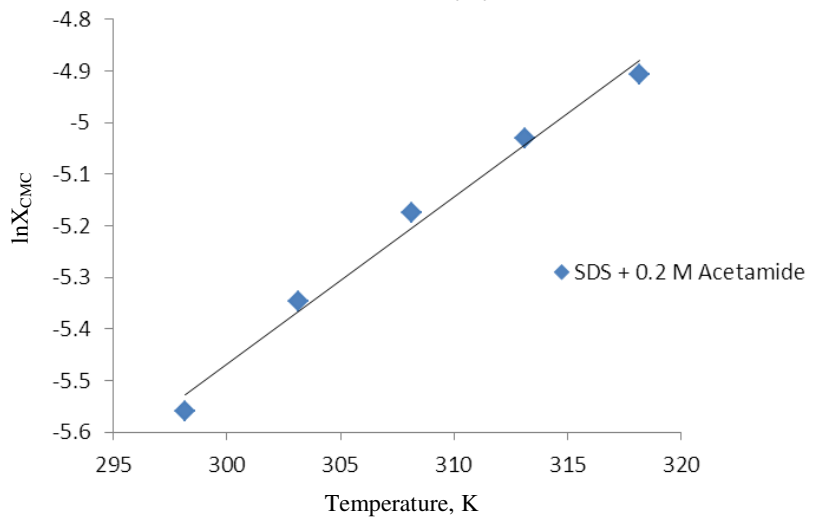

Figure 6. Effect of $0.2 \mathrm{M}$ acetamide on $\ln \mathrm{X}_{\mathrm{cmc}}$ of SDS at different temperatures

Determination of degree of ionization $(\beta)$

The degree of ionization $(\beta)$ of the micelles can be estimated conductometrically from the ratio of the slopes of the two linear segments above and below CMC of specific conducticity versus surfactant concentration ${ }^{20-29}$ and hence, the degree of counterion association, is given as $\alpha=1-\beta$. This simple method is quite satisfactory in providing quantitative estimation of $\beta$, 
as reported by Buckingham and co-workers ${ }^{30}$. Further, the goodness of the method was verified by et al., ${ }^{31}$ and also by Bandyopathyay and Moulik $^{32}$ who have estimated $\beta$ by using ion-selective membrane electrode and found that the values of $\beta$ thus obtained are in good agreement with those obtained conductometrically. However, in fact like $\mathrm{CMC}^{20,33}$, the degree of counter ion dissociation $\beta$ or, in turn. The counter-ion association constant $(\alpha)$ is obtained from the relation, $\alpha=1-\beta^{34}$. As a result, the values of $\alpha$ for $\mathrm{Na}^{+}$ions bond in SDS micelles are reported to lie in the range $0.46-0.86^{35}$ in aqueous medium, depending on the experimental technique employed (electromotive force, light scattering, mass action model, equilibrium dialysis, osmotic coefficient, electrophoresis and zeta potential). Our results lie in the range $0.29-0.81$ of $\beta$ for variation of degree of ionization $(\beta)$ with temperature in the presence of water and in $0.2 \mathrm{M}, 0.4 \mathrm{M}$ and $0.6 \mathrm{M}$, urea and acetamide, are shown in Figure 7 and 8.

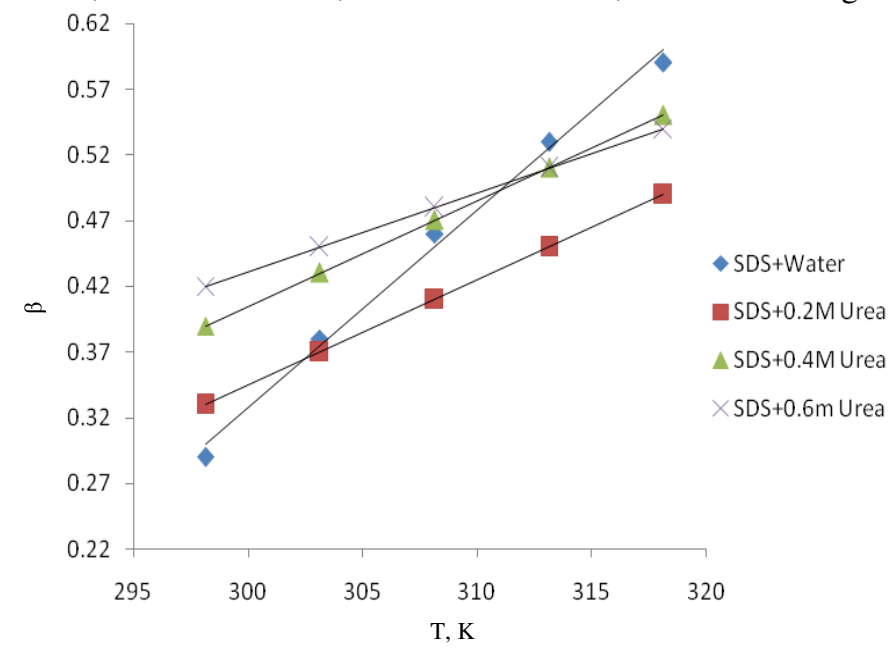

Figure 7. Variation of degree of ionization $(\beta)$ of SDS with temperature in presence of 0.2 , 0.4 and $0.6 \mathrm{M}$ urea

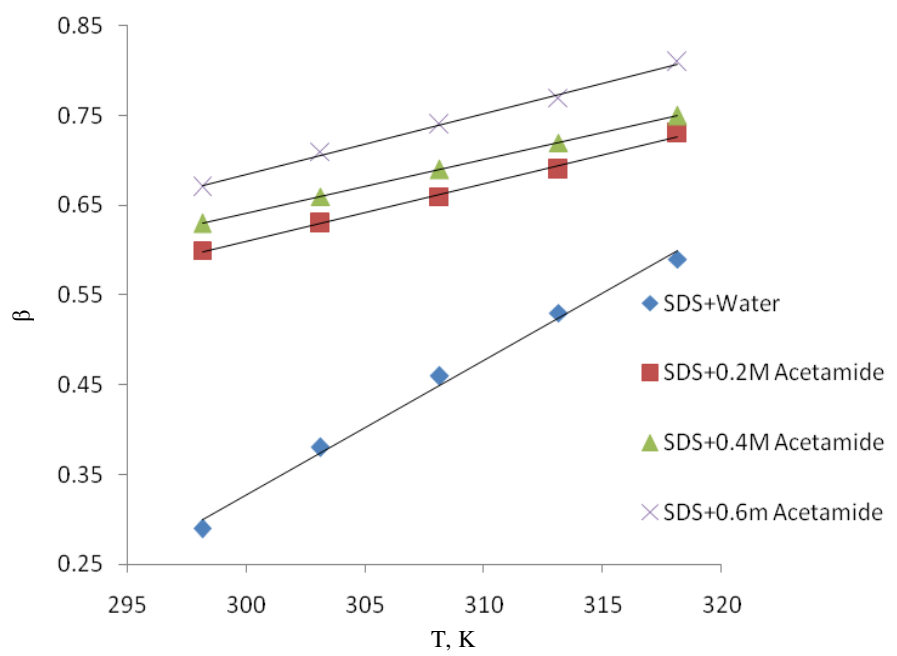

Figure 8. Variation of degree of ionization $(\beta)$ of SDS with temperature in presence of 0.2 , 0.4 and $0.6 \mathrm{M}$ acetamide 
$\mathrm{Na}^{+}$ions bonded to SDS micelles (Table 3) in aqueous medium determined conductometrically at $298.15 \mathrm{~K}$ is fairly good and lies in the reported range.The values of $\beta$ are included in Table 1 and 2 and its variation with temperature is shown in Figure 7 and 8 . It is evident from Table 1 and 2 that both CMC and $\beta$ for the investigated systems increase with an increase in the temperature. The increase in thermal energy due to the rise temperature enhances the ionization of the ionic surfactant SDS and thereby an increase in $\beta$ with temperature is obvious. Similar results have also been reported for the variation of CMC and $\beta$ for SDS in presence and absence of additives in aqueous medium by others ${ }^{25,20}$. In the presence of the additives urea and acetamide, the values of degree of ionization $\beta$ are found to increase from urea to acetamide, as shown in Figure 7 and 8 . The total free energy per surfactant molecule associated with forming the micelle is given by the relation ${ }^{36,37}$.

$$
\Delta \mathrm{G}_{\mathrm{m}}{ }^{0}=\mathrm{RT} \ln \mathrm{X}_{\mathrm{CMC}}
$$

In presence of an additive, the free energy $\Delta \mathrm{G}_{\mathrm{m}}^{0}$ consist of the interactions of SDS-SDS, additive-SDS and additive-additive. It is cited in literature that non electrolytes influence the micellar properties of ionic surfactants by changing structure of the solvent and the surfactant aggregates.

Moreover, the process of micellization is a consequence chiefly of hydrophobic interaction which is hindered by the forces of mutual repulsion acting between the hydrophilic parts (the ionic head groups) of surfactant molecules.

However in the present case, urea/acetamide-water (solute-solvent) interactions dominate in preference to water-water (solvent-solvent) interactions and therefore the formation of iceberg structure around surfactant monomers due to hydrophobic interaction is thus prohibited leading to their cluster formation.

\section{Thermodynamic of micellization}

In order to quantify how addition of urea and acetamide affects the micellization of SDS, the standard molar Gibbs free energy, enthalpy and entropy of micellization were calculated by means of the equilibrium model for the micelle formation and temperature dependence of CMC. The change of the standard molar Gibbs free energy, $\Delta \mathrm{G}_{\mathrm{m}}{ }^{0}$ for ionic and non -ionic surfactant solutions were calculated by using the following equations (1) and (2) respectively ${ }^{38,39}$.

$$
\begin{aligned}
\Delta \mathrm{G}_{\mathrm{m}}{ }^{0} & =(2-\beta) \mathrm{RT} \ln \mathrm{X}_{\mathrm{CMC}} \\
\Delta \mathrm{G}_{\mathrm{m}}{ }^{0} & =\mathrm{RT} \ln \mathrm{X}_{\mathrm{CMC}}
\end{aligned}
$$

Where $\beta$ is the micellar ionization degree, $\mathrm{R}$ is the gas constant $\left(8.314 \mathrm{~J} \mathrm{~K}^{-1} \mathrm{~mole}^{-1}\right), \mathrm{T}$ is the Kelvin temperature and $\mathrm{X}$ is the value of CMC expressed in mole fraction unit ${ }^{40}$. For this calculation, values of the CMC and $\beta$ obtained by Carpena's method were used. The corresponding standard molar enthalpy, $\Delta \mathrm{H}_{\mathrm{m}}{ }^{0}$ is given by ${ }^{40}$.

$$
\Delta \mathrm{H}_{\mathrm{m}}{ }^{0}=-\mathrm{RT}^{2}\left[(2-\alpha)\left\{\delta \ln \mathrm{X}_{\mathrm{CMC}} / \delta \mathrm{T}\right\}-\ln \mathrm{X}_{\mathrm{CMC}}(\delta \alpha / \delta \mathrm{T})\right\}
$$

The changes of standard molar enthalpy of micellization, $\Delta \mathrm{H}_{\mathrm{m}}{ }^{0}$ may be obtained from equation (3), if the dependences of the $\ln \mathrm{X}_{\mathrm{CMC}}$ as well as $\alpha$ on temperature are known. With this purpose, $\ln \mathrm{X}_{\mathrm{CMC}}$ was plotted against $\mathrm{T}$ and the slope at each temperature was taken as $\left\{\delta \ln \mathrm{X}_{\mathrm{CMC}} / \delta \mathrm{T}\right\}$. The obtained dependence, $\ln \mathrm{X}_{\mathrm{CMC}}=\mathrm{f}(\mathrm{T})$, is polynomial $\left(\mathrm{r}^{2}=0.9989\right)$. Note that second term in equation (3) can be neglected due to the fact that values of $\alpha$ vary slightly with temperature. The change of the standard molar entropy, $\Delta \mathrm{S}_{\mathrm{m}}{ }^{0}$ was calculated from equation,

$$
\Delta \mathrm{S}_{\mathrm{m}}{ }^{0}=\Delta \mathrm{H}_{\mathrm{m}}{ }^{0}-\Delta \mathrm{G}_{\mathrm{m}}{ }^{0} / \mathrm{T}
$$


The thermodynamic parameter of micellization for SDS in water and in presence of additives, urea and acetamide at different temperature are summarized in Table 3 and Table 4. For amphoteric and ionic surfactants, $\Delta \mathrm{G}_{\mathrm{m}}{ }^{0}$ has been reported to be between -23 and $-42 \mathrm{~kJ}$ $\mathrm{mol}^{-1}$ at $298.15 \mathrm{~K}^{41}$.

Table 3. $\Delta \mathrm{G}_{\mathrm{m},}^{0} \Delta \mathrm{H}_{\mathrm{m}}^{0}$ and $\Delta \mathrm{S}_{\mathrm{m}}^{0}$ of pure SDS and SDS + [Urea] at different concentrations and at different temperatures

\begin{tabular}{|c|c|c|c|c|c|}
\hline & \multicolumn{5}{|c|}{$\mathrm{T}, \mathrm{K}$} \\
\hline & 298.15 & 303.15 & 308.15 & 313.15 & 318.15 \\
\hline \multicolumn{6}{|l|}{ SDS } \\
\hline$-\Delta \mathrm{G}_{\mathrm{m}}^{0} \mathrm{~kJ} \mathrm{~mol}^{-1}$ & 20.80 & 19.58 & 18.54 & 17.59 & 17.00 \\
\hline$-\Delta \mathrm{H}_{\mathrm{m}}^{0} \mathrm{~kJ} \mathrm{~mol}^{-1}$ & 5.38 & 5.77 & 5.98 & 6.31 & 6.52 \\
\hline$\Delta \mathrm{S}_{\mathrm{m}}^{0} \mathrm{~kJ} \mathrm{~mol}^{-1} \mathrm{~K}^{-1}$ & 0.088 & 0.084 & 0.080 & 0.076 & 0.074 \\
\hline \multicolumn{6}{|l|}{$\mathrm{SDS}+0.2 \mathrm{M}$ Urea } \\
\hline$-\Delta G_{\mathrm{m}}^{0} \quad \mathrm{~kJ} \mathrm{~mol}^{-1}$ & 20.82 & 20.15 & 19.52 & 19.00 & 18.43 \\
\hline$-\Delta \mathrm{H}_{\mathrm{m}}^{0} \quad \mathrm{~kJ} \mathrm{~mol}^{-1}$ & 5.68 & 5.74 & 5.78 & 5.82 & 5.85 \\
\hline$\Delta \mathrm{S}_{\mathrm{m}}^{0} \mathrm{~kJ} \mathrm{~mol}^{-1} \mathrm{~K}^{-1}$ & 0.051 & 0.048 & 0.045 & 0.042 & 0.039 \\
\hline \multicolumn{6}{|l|}{$\mathrm{SDS}+0.4 \mathrm{M}$ Urea } \\
\hline$-\Delta \mathrm{G}_{\mathrm{m}}^{0} \quad \mathrm{~kJ} \mathrm{~mol}^{-1}$ & 20.65 & 19.90 & 19.23 & 18.58 & 18.06 \\
\hline$-\Delta \mathrm{H}_{\mathrm{m}}^{0} \quad \mathrm{~kJ} \mathrm{~mol}^{-1}$ & 6.30 & 6.35 & 6.40 & 6.43 & 6.46 \\
\hline$\Delta \mathrm{S}_{\mathrm{m}}^{0} \mathrm{~kJ} \mathrm{~mol}^{-1} \mathrm{~K}^{-1}$ & 0.048 & 0.044 & 0.041 & 0.039 & 0.036 \\
\hline \multicolumn{6}{|l|}{ SDS + 0.6 M Urea } \\
\hline$-\Delta \mathrm{G}_{\mathrm{m}}^{0} \quad \mathrm{~kJ} \mathrm{~mol}^{-1}$ & 20.98 & 20.21 & 19.58 & 19.03 & 18.50 \\
\hline$-\Delta \mathrm{H}_{\mathrm{m}}^{0} \mathrm{~kJ} \mathrm{~mol}^{-1}$ & 7.53 & 7.64 & 7.74 & 7.83 & 7.92 \\
\hline$\Delta \mathrm{S}_{\mathrm{m}}^{0} \mathrm{~kJ} \mathrm{~mol}^{-1} \mathrm{~K}^{-1}$ & 0.045 & 0.041 & 0.038 & 0.035 & 0.033 \\
\hline
\end{tabular}

Table 4. $\Delta \mathrm{G}_{\mathrm{m}}^{0} \Delta \mathrm{H}_{\mathrm{m}}^{0}$ and $\Delta \mathrm{S}_{\mathrm{m}}^{0}$ of pure SDS and SDS + [Acetamide] at different concentrations and at different temperatures

\begin{tabular}{|c|c|c|c|c|c|}
\hline & \multicolumn{5}{|c|}{$\mathrm{T}, \mathrm{K}$} \\
\hline & 298.15 & 303.15 & 308.15 & 313.15 & 318.15 \\
\hline \multicolumn{6}{|c|}{ SDS + 0.2 M Acetamide } \\
\hline$-\Delta \mathrm{G}_{\mathrm{m}}^{0} \mathrm{~kJ} \mathrm{~mol}^{-1}$ & 19.30 & 18.43 & 17.76 & 17.15 & 16.48 \\
\hline$-\Delta \mathrm{H}_{\mathrm{m}}^{0} \quad \mathrm{~kJ} \mathrm{~mol}^{-1}$ & 7.63 & 7.71 & 7.80 & 7.87 & 7.88 \\
\hline$\Delta \mathrm{S}_{\mathrm{m}}^{0} \quad \mathrm{~kJ} \mathrm{~mol}^{-1} \mathrm{~K}^{-1}$ & 0.039 & 0.035 & 0.032 & 0.029 & 0.027 \\
\hline \multicolumn{6}{|c|}{ SDS + 0.4 M Acetamide } \\
\hline$-\Delta \mathrm{G}_{\mathrm{m}}^{0} \quad \mathrm{~kJ} \mathrm{~mol}^{-1}$ & 19.82 & 18.77 & 17.94 & 17.24 & 16.63 \\
\hline$-\Delta \mathrm{H}_{\mathrm{m}}^{0} \quad \mathrm{~kJ} \mathrm{~mol}^{-1}$ & 9.33 & 9.43 & 9.53 & 9.61 & 9.69 \\
\hline$\Delta \mathrm{S}_{\mathrm{m}}^{0} \mathrm{~kJ} \mathrm{~mol}^{-1} \mathrm{~K}^{-1}$ & 0.035 & 0.030 & 0.027 & 0.024 & 0.021 \\
\hline \multicolumn{6}{|c|}{ SDS + 0.6 M Acetamide } \\
\hline$-\Delta \mathrm{G}_{\mathrm{m}}^{0} \mathrm{~kJ} \mathrm{~mol}^{-1}$ & 20.64 & 18.98 & 17.95 & 17.12 & 16.29 \\
\hline$-\Delta \mathrm{H}_{\mathrm{m}}^{0} \quad \mathrm{~kJ} \mathrm{~mol}^{-1}$ & 11.99 & 12.03 & 12.41 & 12.24 & 12.22 \\
\hline$\Delta \mathrm{S}_{\mathrm{m}}^{0} \mathrm{~kJ} \mathrm{~mol}^{-1} \mathrm{~K}^{-1}$ & 0.029 & 0.022 & 0.018 & 0.015 & 0.012 \\
\hline
\end{tabular}

The free energy values for SDS in water and in presence of aqueous urea and acetamide fall within this range. Figure 9 and 10 shows the increase in free energy with temperature for $\mathrm{SDS}$ in water and in presence of additives, suggesting that an increase in temperature disfavors micellization. 


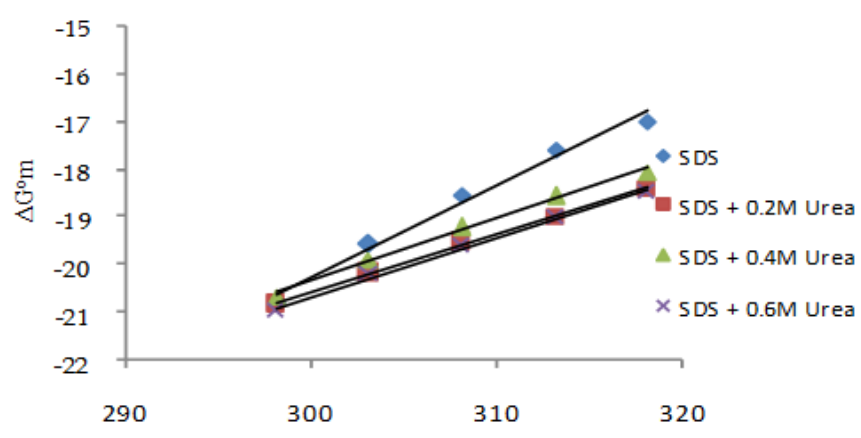

$\mathrm{T}, \mathrm{K}$

Figure 9. Effect of urea on free energy of micellization of $\operatorname{SDS}\left(\Delta \mathrm{G}^{0}{ }_{\mathrm{m}}\right)$ with temperature

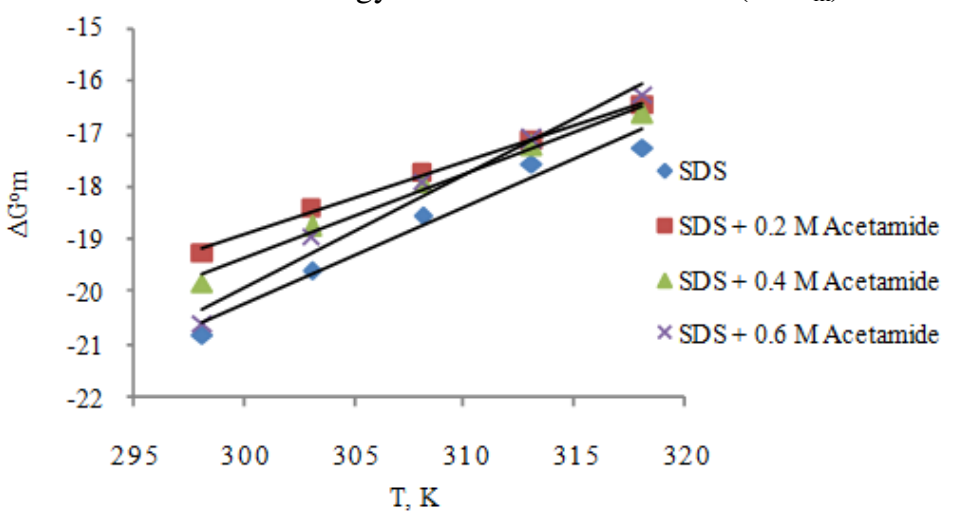

Figure 10. Effect of acetamide on free energy of micellization of SDS $\left(\Delta \mathrm{G}^{0}{ }_{\mathrm{m}}\right)$ with temperature

This supports the change in CMC with temperature. At a given a temperature, $\Delta \mathrm{G}_{\mathrm{m}}{ }^{0}$ is found to increase from urea to acetamide (Table 3 and 4). This can be explained by considering the degree of ionization, $\beta$ of SDS in presence of urea and acetamide. As the value of $\beta$ tends to increase from urea to acetamide (Table 1 and 2), the availability of counter ions, $\mathrm{Na}^{+}$for interaction with the surfactant head group decreases. This would cause increased electrostatic repulsion between the head groups, thereby, increasing the free energy of micellization, $\Delta \mathrm{G}_{\mathrm{m}}{ }^{0}$ in the sequence: urea <acetamide at a given temperature. The negative values of, $\Delta \mathrm{G}_{\mathrm{m}}{ }^{0}$ are mainly attributed to the positive values of, $\Delta \mathrm{S}_{\mathrm{m}}{ }^{0}$ than $\Delta \mathrm{H}_{\mathrm{m}}{ }^{0}$. Therefore, the micellization process is governed primarily by the entropy gain and driving force for the process is the tendency of the hydrophobic group of the SDS to transfer from the solvent environment to the interior of the micelle ${ }^{24}$. At higher temperatures, disruption of the structured water surrounding the hydrophobic group may be responsible for the entropy increase. As $\Delta \mathrm{G}_{\mathrm{m}}{ }^{0}$ is the sum of the enthalpic, $\Delta \mathrm{H}_{\mathrm{m}}{ }^{0}$ and entropic, $\mathrm{T} \Delta \mathrm{S}_{\mathrm{m}}{ }^{0}$ contributions. It reveals that in presence of urea and acetamide, the entropic contribution $\mathrm{T} \Delta \mathrm{S}_{\mathrm{m}}{ }^{0}$ is increased while enthalpic contribution $\Delta \mathrm{H}_{\mathrm{m}}{ }^{0}$ gets decreased with increase in temperature. In the presence of urea and acetamide, a rise in temperature does not significantly affect the enthalpic and entropic contributions to $\Delta \mathrm{G}_{\mathrm{m}}{ }^{0}$. It is due to the fact that in presence of urea and acetamide, the changes in $\Delta \mathrm{S}_{\mathrm{m}}{ }^{0}$ and $\Delta \mathrm{H}_{\mathrm{m}}{ }^{0}$ with temperature are quite appreciable. As a result, the entropic $\mathrm{T} \Delta \mathrm{S}_{\mathrm{m}}{ }^{0}$ and enthalpic $\Delta \mathrm{H}_{\mathrm{m}}{ }^{0}$ contributions to $\Delta \mathrm{G}_{\mathrm{m}}{ }^{0}$ in presence of urea and acetamide are almost in significant with increase in temperature. 


\section{Conclusion}

The effect of urea and acetamide on the micellization SDS in an aqueous medium has been investigated at different temperatures. The critical micelle concentration of SDS increases with increase in temperature. While it exhibits an opposite trend as the hydrophobic character increase from urea to acetamide. Using the equilibrium model or mass action model, the values of standard free energy $\left(\Delta \mathrm{G}_{\mathrm{m}}^{0}\right)$, enthalpy $\left(\Delta \mathrm{H}_{\mathrm{m}}^{0}\right)$ and entropy $\left(\Delta \mathrm{S}_{\mathrm{m}}^{0}\right)$ were calculated. In the presence of urea /acetamide, $\left(\Delta \mathrm{G}_{\mathrm{m}}^{0}\right)$ is found to increase within temperature and that it increases also from urea to acetamide at a given temperature. Negative values of $\Delta \mathrm{G}_{\mathrm{m}}^{0}$ are suggesting that micellization process is governed primarily by entropy gain. The observed behaviors of these parameters may be attributed to the interactions of urea /acetamide with water and surfactant molecules and also due to the possible solubilization of additives in the palisade layer of micelles.

It can be concluded from the conductivity and thermodynamic results that the mixture formed in different concentrations of urea, acetamide and SDS are an ideal system, shown through the variation in aggregation behavior and other obtained values. Micellar interactions of SDS in aqueous-additives such as urea and acetamide solutions by conductometric and thermodynamic analysis provided valuable information regarding structural changes in the constituent molecules of urea and acetamide as well as surfactant which are further characterized by hydrophobic interaction as well as hydrophobic hydration. The decrease in $\mathrm{CMC}$ in the presence of additives is due to the establishment of additional hydrophobic interactions between hydrophobic parts of surfactant and additives. The calculated thermodynamic parameter $\mathrm{T} \Delta \mathrm{S}_{\mathrm{m}}^{0}$ was found larger than $\Delta \mathrm{H}_{\mathrm{m}}^{0}$ suggesting micellization is entropy driven. Moreover, negative enthalpy $\left(\Delta \mathrm{H}_{\mathrm{m}}^{0}\right)$ and Gibbs free energy $\left(\Delta \mathrm{G}_{\mathrm{m}}^{0}\right)$ values indicated that the system is feasible and is of exothermic nature while positive $\Delta S^{0}$ values interpret that the driving force for micellization is entropic i.e. the tendency of hydrophobic group of surfactant to transfer from solvent system to the interior of micelle.

\section{Acknowledgement}

The author (ADM) is thankful to UGC, WRO, Pune for financial assistance as Minor Research Project (F-47-627/13). The authors are thankful to Hon'ble Principal and Head, Department of Chemistry, Z.B. Patil College, Dhule. Also Hon'ble Principal and Head Department of Chemistry, Kisan Arts Commerce and Science College, Parola Dist. Jalgaon for providing necessary laboratory facilities and encouragement.

\section{References}

1. Gunnrsson G, Jonsson B and Wennerstrom H, J Phys Chem., 1980, 84, 3114 -3121.

2. Kundryashov E, Kapustina T, Morrissey S, Bucking Vand Dawson K, J Colloid Interface Sci., 203, 1(1), 59-68; DOI:10.1006/jcis.1998.5333

3. Sarason G and Chouhan I, Int J Sci and Res., 2015, 4(3), 2319-7064.

4. Ruiz C C, Molina Bolivar J A, Aguir J and Peula-Garcia J M, Colloids Surf A: Physicochem Engg Aspect., 2004, 249(1-3), 35-39; DOI:10.1016/j.colsurfa.2004.08.045

5. Qiu X, Fang W, Lei Q and Lin R K, J ChemEng Data, 2008, 53(4), 942-945; DOI:10.1021/je7006082

6. Sharma K S, Patil S R, Rakshit A K, Glenn K, Doiron M, Palepu R M and Hassan P A. J Phys Chen B, 2004, 108(34),12804-12812; DOI:10.1021/jp048294o

7. Dixit S B, Bhasin R, Rajasekaran E and Jayaram B, J Chem Soc Faraday Trans., 1997, 93, 1105-1113; DOI:10.1039/A603913H

8. Lehinger A L, Nelson D L and Cox M M, Worth Publishers, USA, 1993. 
9. $\quad$ Singh S K and Kishore N, J Phys Chem B, 2006, 110(19), 9728-9737.

10. Singh S K, Kundu A and Kishor N, J Chem Thermodyn, 2004, 36(1), 7-16; DOI:10.1016/j.jct.2003.09.010

11. Deep S and Ahluwalia J C, Phys Chem Phys., 2001, 3, 4583-4591.

12. Clifford A and Bunton, Bull Hist Chem., 1996, 19, 72-76.

13. Malliaris A, J Phys Chem., 1987, 91(26), 6511-6515; DOI:10.1021/j100310a018

14. Zho H, Biophys Chem., 2006, 122(3),157-183; DOI:10.1016/j.bpc.2006.03.008

15. Burke S E, Andrecyk S L and Palepu R, Colloid Polym Sci., 2001, 279, 131-138

16. Chauhan M S, Kumar G, Kumar A and Chauhan S, Colloids Surf A: Physicochem Engg Aspect., 2000, 166(1-3), 51-57; DOI:10.1016/S0927-7757(99)00460-4

17. Bakshi M S, Bull Chem Soc Jpn., 1996, 69(10), 2723-2729; DOI:10.1246/bcsj.69.272

18. De Lisi R and Milioto S, Chem Soc Rev., 1994, 23, 67-73; DOI:10.1039/CS9942300067

19. Fujiwara M, Okano T, Nakashima T H, Nakamura A A and Sugihara G, Colloid Polym Sci., 1997, 275(5), 474-479; DOI:10.1007/s003960050106

20. Ray G B, Ghosh S and Moulik S P, J Surfact Deterg. 2009, 12(2), 131-143; DOI:10.1007/s11743-008-1105-3

21. Sharma V K. Yadav O P and Singh J, Colloids Surf A: Physicochem Engg Aspect., 1996, 110(1), 23-35; DOI:10.1016/0927-7757(95)03409-9

22. Markarian S A, Harutyunyan L R, Harutanyan L R, Harutanyan R S, J Solution Chem., 2005, 34(3), 361-368; DOI:10.1007/s10953-005-3056-x

23. Pradhan P C and Sinha B K, Indian J Chem., 1987, 26A, 691-692.

24. Rosen K J, Wiley, New York, 1989.

25. Mehta S K, Choudhary S, Bhasin K K Kumar R and Aratono M, Colloids Surf A: Physicochem Engg Aspect., 2007, 304(1-3), 88-95; DOI:10.1016/j.colsurfa.2007.04.031

26. Rakshit A K and Sharma B, Collioid Polym Sci., 2003, 281(1), 45-51; DOI:10.1007/s00396-002-0743-7

27. Yu L, Lu T, Luan Y K. Liu J and Xu G Y Colloids Surf A: Physicochem Engg Aspect., 2005, 257-258, 375-379; DOI:10.1016/j.colsurfa.2004.10.066

28. Varun B, Poonam S, Chauhan M S and Chauhan S, J Saudi Chem Soc., 2012, DOI:10.1016/j.jscs.2012.09.008

29. Ray G B, Chakraborty I, Ghosh S, Moulik S and Palepu R, Langmuir., 2005, 21(24), 10958-10967; DOI:10.1021/la051509g

30. Buckingham S A, Garvey C J and Warr G G, J Phys Chem., 1993, 97, 10236-10244; DOI:10.1021/j100141a054

31. Kale K M, Cussler E L and Evans D F, J Phys Chem., 1980, 84, 593-598

32. Bandopadhyay A, Moulik S P, Colloid Polym Sci., 1988, 266(5), 455-461; DOI:10.1007/BF01457263

33. Bazito R C and El Scoud O A, Langmuir, 2002, 18(11), 4362-4366; DOI:10.1021/la0117552

34. Sansanwal P K, Journal of Scientific and Industrial Research, 2006, 65, 57-64.

35. Sasaki T, Hottori Sasaki J and Nukina K, Chem Soc Jpn., 1975, 48, 1397-1403.

36. Evans D F and Ninham B W, J Phy Chem., 1983, 87, 5025-5032.

37. Uneo M, Tsao Y H, Joyce B E and Evans D F, J Solution Chem., 1992, 21(1), 445457; DOI:10.1007/BF00649698

38. Patil S R and Rakshit A K, J Indian Chem Soc., 2003, 80(4), 345-350.

39. Moulik S P, Curr Sci., 1996, 71(5), 368-376.

40. Rosen M J, New York, 2004.

41. Kang K H, Kim H U and Lim K H, Colloids Surf A: Physicochem Engg Aspect., 2001, 189(1-3), 113-121; DOI:10.1016/S0927-7757(01)00577-5 